\title{
PENGENDALIAN PERSEDIAAN BAHAN BAKU DENGAN METODE ECONOMIC ORDER QUANTITY (EOQ) PADA PT. BUMI SARIMAS INDONESIA
}

\author{
ATRI NODI MAIZA PUTRA \\ Universitas Muhamadiyah Sumatera Barat \\ atrinodafe@gmail.com
}

\begin{abstract}
Abstrak: Coconut raw material processing techniques at PT. Bumi Sarimas Indonesia has followed the procedures established by the company, starting from purchasing, receiving, collecting and storing, releasing, preparing raw materials and processing coconut raw materials for coconut milk production. The use of coconut meat as raw material for coconut milk production at PT. Bumi Sarimas Indonesia Kabupaten Padang Pariaman is generally inefficient. The amount of economical and optimal raw material needs using the EOQ method in 2014 and 2015 was 1,505 tons with an order frequency of 46 times a year and 1,467 tons with a frequency of ordering 48 times a year. The safety stock quantity in 2014 and 2015 using the EOQ method, the quantity of safety stock is 3,164.7 tons and 2,588.9 tons. Reordering (Re Order Point) according to EOQ calculations in 2014 and 2015 was at 3,552.3 tons and 2,986.7 tons. The managerial implementation of PT. Bumi Sarimas Indonesia regarding the efficient use of raw materials can be carried out by planning (planning) the need for the use of raw materials, organizing (organizing) the field of coconut milk production process activities, actuating (implementing) activities in accordance with the company's standard operating procedures (SOP) and controling (supervision) of raw materials, control of the machines used.
\end{abstract}

Keywords: Control, Inventories, Raw Materials, EOQ.

Abstrak: Teknik pengolahan bahan baku kelapa pada PT. Bumi Sarimas Indonesia sudah mengikuti prosedur yang ditetapkan perusahaan mulai dari pembelian, penerimaan, pengumpulan dan penyimpanan, pengeluaran, persiapan bahan baku serta proses pengolahan bahan baku kelapa untuk produksi santan. Penggunaan bahan baku daging kelapa terhadap produksi hasil santan di PT. Bumi Sarimas Indonesia Kabupaten Padang Pariaman secara umum belum efisien. Jumlah kebutuhan bahan baku yang ekonomis dan optimal dengan menggunakan metode EOQ pada tahun 2014 dan tahun 2015 adalah 1.505 Ton dengan frekuensi pemesanan 46 kali dalam satu tahun dan 1.467 Ton dengan frekuensi pemesanan 48 kali dalam setahun. Kuantitas persediaan pengaman atau Safety stock pada tahun 2014 dan 2015 dengan menggunakan metode EOQ kuantitas persediaan pengaman adalah 3.164,7 Ton dan 2.588,9 Ton. Pemesanan kembali (Re Order Point) menurut perhitungan EOQ pada tahun 2014 dan 2015 berada pada titik 3.552,3 Ton dan 2.986,7 Ton. Implementasi manajerial PT. Bumi Sarimas Indonesia tentang penggunaan bahan baku yang efisien dapat dilakukan dengan planning (perencanaan) terhadap kebutuhan penggunaan bahan baku, organizing (pengorganisasian) terhadap bidang kegiatan proses produksi santan kelapa, actuating (pelaksanaan) kegiatan yang sesuai dengan standar operasionan prosedur (SOP) perusahaan dan controling (pengawasan) terhadap bahan baku, kontrol pada mesin yang digunakan.

Kata Kunci: Pengendalian, Persedian, Bahan Baku, EOQ. 


\section{A. Pendahuluan}

PT. Bumi Sarimas Indonesia adalah perusahaan yang bergerak dibidang manufaktur yang memproduksi bahan baku menjadi barang setengah jadi maupun barang jadi seperti, Cocomas, Nata de Coco, dan Tepung Kelapa. Selama ini PT. Bumi Sarimas Indonesia tersebut dalam kebijaksanaan pengadaan bahan baku belum menerapkan metode EOQ. Pembelian bahan baku hanya berdasarkan permintaan pasar atau order dari konsumen. Terkadang perusahaan membeli bahan baku dalam jumlah yang relatif besar, sehingga akan menyebabkan penumpukkan bahan baku.

\section{B. Metode Penelitian}

Langkah-langkah analisis penelitian ini dilakukan dengan terlebih dahulu mengumpulkan dan menghitung data-data yang akan diperlukan, dalam upaya efisiensi penggunaan biaya persediaan. Yaitu diantaranya: Mencatat perhitungan bahan baku yang dibutuhkan oleh perusahaan berdasarkan jumlah kebutuhan atau permintaan dari petani singkong dalam satu tahunnya. Mencatat perhitungan biaya pemesanannya dalam setiap kali pesan. Mencatat perhitungan biaya penyimpanan dari nilai persediaan yang akan tersedia. Menghitung jumlah pemesanan yang paling ekonomis (EOQ), dengan menggunakan rumus : EOQ $=\frac{\sqrt{2 D S}}{\mathrm{H}}$ Dimana :

$\mathrm{D}=$ Penggunaan atau permintaan yang diperkirakan per periode waktu

$\mathrm{S}=$ Biaya per pesanan

$\mathrm{H}$ = Biaya penyimpanan per unit per tahun

\section{Hasil dan Pembahasan}

\section{Kebutuhan Bahan Baku}

Dua tahun ini kebutuhan bahan baku kelapa diperoleh dari beberapa supplier. Kebijakan pengadaan bahan baku dilakukan sesuai dengan permintaan pasar. Akibat kebijakan ini permintaan bahan baku tidak stabil disesuaikan kebutuhan.

Berikut ini tabel jumlah kebutuhan bahan baku tahun 2014 dan 2015 pada PT. Bumi Sarimas Indonesia.

\begin{tabular}{|l|l|c|c|}
\hline \multirow{2}{*}{ No } & \multirow{2}{*}{ Bulan } & \multicolumn{2}{|c|}{$\begin{array}{c}\text { Jumlah Kebutuhan Bahan Baku } \\
\text { (Ton) }\end{array}$} \\
\cline { 3 - 4 } & & $\mathbf{2 0 1 4}$ & $\mathbf{2 0 1 5}$ \\
\hline 1. & Januari & $2.401,5$ & $3.701,6$ \\
\hline 2. & Februari & $2.871,9$ & $3.441,5$ \\
\hline 3. & Maret & $4.100,3$ & $4.264,2$ \\
\hline 4. & April & $4.203,5$ & $5.175,1$ \\
\hline 5. & Mei & 6.711 & $6.503,4$ \\
\hline 6. & Juni & $6.691,2$ & $7.926,3$ \\
\hline 7. & Juli & $6.812,1$ & $7.838,6$ \\
\hline 8. & Agustus & $6.332,3$ & $8.369,7$ \\
\hline 9. & September & $9.231,5$ & $6.112,8$ \\
\hline 10. & Oktober & $7.222,5$ & $6.717,2$ \\
\hline
\end{tabular}




\begin{tabular}{|c|c|c|c|}
\hline 11. & November & 6.981 & $5.697,3$ \\
\hline 12. & Desember & $5,612,6$ & $5.277,9$ \\
\hline \multicolumn{2}{|c|}{ Jumlah } & $\mathbf{6 9 . 1 7 1 , 4}$ & $\mathbf{7 1 . 0 2 5 , 6}$ \\
\hline
\end{tabular}

Tabel Kebutuhan bahan baku kelapa tahun 2014 dan 2015 pada PT.Bumi Sarimas Indonesia

\section{Analisis Metode EOQ}

Perhitungan dengan menggunakan metode Economic Order Quantity (EOQ):

a. Tahun 2014

$$
\begin{aligned}
& \mathrm{S}=\mathrm{Rp} .48 .000 \\
& \mathrm{D}=69.171,4 \text { Ton } \\
& \mathrm{H}=\mathrm{Rp} .2 .933
\end{aligned}
$$$$
\mathrm{EOQ}=\sqrt{\frac{2 . S . L}{H}}
$$$$
\mathrm{EOQ}=\sqrt{\frac{2(48.000)(69.171,4)}{2.933}}
$$$$
\mathrm{EOQ}=\sqrt{\frac{6.640 .416 .000}{2.933}}
$$$$
\mathrm{EOQ}=\sqrt{2.264 .035,46}
$$$$
\mathrm{EOQ}=1.504,67
$$

b. Tahun 2015

$$
\begin{aligned}
& \mathrm{S}=\text { Rp. } 48.000 \\
& \mathrm{D}=71.025,6 \text { Ton } \\
& \mathrm{H}=\mathrm{Rp} .3 .169
\end{aligned}
$$

$\begin{array}{ll}\mathrm{EOQ}= & \sqrt{\frac{2 . S . D}{H}} \\ \mathrm{EOQ}= & \sqrt{\frac{2(48000)(71.025,6)}{3.169}} \\ \mathrm{EOQ}= & \sqrt{\frac{6.818 .457 .600}{3.169}} \\ \mathrm{EOQ}= & \sqrt{2.151 .611,74} \\ \mathrm{EOQ}=1.466,83 & \end{array}$

\section{Pembelian bahan baku yang ekonomis}

Pembelian bahan baku yang ekonomis yaitu dengan melakukan pembelian secara teratur maka perusahaan akan menanggung biaya-biaya pengadaan bahan baku yang minimal. Langkah-langkah dalam perhitungan dengan menggunakan metode Economic Order Quantity (EOQ) adalah sebagai berikut:

a. Tahun 2014

1. Biaya penyimpanan bahan baku perunit $(\mathrm{H}) \mathrm{Rp} .2 .933$ / Ton

2. Total kebutuhan bahan baku (D) 69.171,4 Ton

3. Biaya pesan sekali pesan (S) Rp.48.000 
b. Tahun 2015

1. Biaya penyimpanan bahan baku perunit $(\mathrm{H}) \mathrm{Rp} \cdot 3.169,3$ / Ton

2. Total kebutuhan bahan baku (D) 71.025,6 Ton

3. Biaya pesan sekali pesan (S) Rp.48.000

Maka besarnya pembelian bahan baku yang ekonomis dapat diperhitungkan dengan metode EOQ sebagai berikut:

a. Tahun 2014

b. Tahun 2015

$$
\begin{aligned}
& Q_{Q P T}=\sqrt{\frac{2 D S}{H}} \\
& Q_{Q P T}=\sqrt{\frac{2(69.171,4)(48000)}{2.933}} \\
& Q_{Q P T}=\sqrt{\frac{6.640 .454 .400}{2.933}} \\
& Q_{Q P T}=\sqrt{2.264 .048,56} \\
& Q_{Q P T}=1.505 \text { Ton }
\end{aligned}
$$

$$
\begin{aligned}
& Q_{Q P T}=\sqrt{\frac{2 D S}{H}} \\
& Q_{Q P T}=\sqrt{\frac{2(71.025,6)(48000)}{3.169,3}} \\
& Q_{Q P T}=\sqrt{\frac{6.818457 .600}{3.169,3}} \\
& Q_{Q P T}=\sqrt{2.151 .408} \\
& Q_{Q P T}=1.467 \text { Ton }
\end{aligned}
$$

\section{Frekuensi pemesanan bahan baku}

Jumlah pemesanan bahan baku yang ekonoms menurut metode Economic Order Quantity (EOQ) sudah diketahui, maka frekuensi pemesanan (F) menurut metode EOQ dapat dihitung dengan cara sebagai berikut:

1. Tahun 2014

$$
\begin{aligned}
& \mathrm{F}=\quad \frac{D}{Q_{Q P T}} \\
& \mathrm{~F}=\quad \frac{69.171,4}{1.505} \\
& \mathrm{~F}=46 \text { kali } \\
& \text { Jadi frekuensi pemesanan bahan baku dilakukan } 46 \text { kali setahun. }
\end{aligned}
$$

2. Tahun 2015

$$
\begin{aligned}
& \mathrm{F}=\frac{D}{Q_{Q P T}} \\
& \mathrm{~F}=\quad \frac{71.025, \epsilon}{1.467} \\
& \mathrm{~F}=48 \text { kali } \\
& \text { Jadi frekuensi pemesanan bahan baku dilakukan } 48 \text { kali setahun. }
\end{aligned}
$$

\section{Total Biaya Per Periode}

Total biaya per periode merupakan penjumlahan dari biaya simpan dan biaya pesan. Total biaya per periode minimum akan tercapai pada saat biaya simpan sama dengan biaya pesan. Pada saat total biaya per periode minimum, maka jumlah pesanan 
tersebut dapat dikatakan jumlah pesanan yang paling ekonomis (EOQ). Untuk menentukan total biaya per periode, maka perlu diketahui datasebagai berikut:

a. Tahun 2014

1. Total kebutuhan bahan baku (D) 69.171,4 Ton

2. Biaya pesan 1 kali pesan (S) Rp.48.000

3. Biaya penyimpanan bahan baku per unit $(\mathrm{H}) \mathrm{Rp} .2 .933$ / Ton

4. Pembelian bahan baku yang ekonomis ( $\left.\quad Q_{Q P T}\right)$ 1.505 Ton Perhitungan biaya per periode adalah sebagai berikut:

$$
\begin{aligned}
\mathrm{TC} & =\quad \frac{Q}{2} H+\frac{D}{Q} S \\
\mathrm{TC} & = \\
\mathrm{TC} & =\text { Rp.2.207.083 } 2.933+\frac{69.171,4}{1.505} 48000 \\
\mathrm{TC} & =\text { Rp.4.413.214 }
\end{aligned}
$$

Jadi total biaya per periode yang telah dihitung dengan menggunakan metode EOQ adalah Rp.4.413.214,-

b. Tahun 2015

1. Total kebutuhan bahan baku (D) 69.171,4 Ton

2. Biaya pesan 1 kali pesan (S) Rp.48.000

3. Biaya penyimpanan bahan baku per unit $(\mathrm{H}) \mathrm{Rp} .2 .933$ / Ton

4. Pembelian bahan baku yang ekonomis $\left(Q_{Q P T}\right)$ 1.505 Ton Perhitungan biaya per periode adalah sebagai berikut:

$$
\begin{aligned}
\mathrm{TC} & =\quad \frac{Q}{2} H+\frac{D}{Q} S \\
\mathrm{TC} & = \\
\mathrm{TC} & =\text { Rp.2.324.681 } 3.169,3+\frac{71.025,6}{1.467} 48000 \\
\mathrm{TC} & =\text { Rp.4.648.627 }
\end{aligned}
$$

Jadi total biaya per periode yang telah dihitung dengan menggunakan metode EOQ adalah Rp.4.648.627,-

\section{Penentuan Persediaan Pengaman}

Persediaan pengaman atau (Safety stock) sangat diperlukan dalam sebuah perusahaan karenan berfungsi untuk melindungi atau menjaga kemungkinan terjadinya kekurangan bahan baku, sehingga memperlancar kegiatan produksi. Dalam perhitungan kegiatan pengaman, rata-rata bahan baku dengan pemakaian bahan baku sesungguhnya dibandingkan kemudian dicari penyimpangannya.

1. Tahun 2014

$$
\begin{aligned}
\text { Safety stock } & =\mathrm{SD} \times \mathrm{Z} \\
& =1.918 \times 1,65 \\
& =3.164,7 \text { Ton }
\end{aligned}
$$

2. Tahun 2015

$$
\begin{aligned}
\text { Safety stock } & =\mathrm{SD} \times \mathrm{Z} \\
& =1.569 \times 1,65 \\
& =2.588,9 \text { Ton }
\end{aligned}
$$

Jadi persediaan bahan baku yang harus disediakan PT. Bumi sarimas Indonesia sebagai persediaan pengaman pada tahun 2014 adalah sebesar 3.164,7 Ton dan tahun 2015 adalah sebesar 2.588,9 Ton. 


\section{Pemesanan Kembali}

Waktu tunggu lead time yang diperlukan perusahaan PT. Bumi Sarimas Indonesia untuk menunggu datangnya bahan baku yang telah dipesan rata-rata 2 hari, waktu paling cepat adalah 1 hari. Dengan rata-rata jumlah hari kerja 357 hari tahun 2014 dan 355 hari tahun 2015. Sebelum menghitung besarnya Re Order Point, perlu dicari tingkat penggunaan bahan baku per hari dapat dihitung dengan cara sebagai berikut:

1. Tahun 2014

$$
\begin{array}{ll}
\mathrm{d} & =\frac{\frac{D}{t}}{69.171,4 \text { Ton }^{\prime}} \\
\mathrm{d} & =\quad \frac{657}{\mathrm{~d}}
\end{array}
$$

Maka titik pemesanan ROP adalah:

$\mathrm{R}=\mathrm{dL}+\mathrm{n}$

$\mathrm{R}=193,8 \times 2+3.164,7$

$\mathrm{R}=387,6+3.164,7$

$\mathrm{R}=3.552,3$ Ton

2. Tahun 2015

$$
\begin{array}{ll}
\mathrm{d} & =\frac{\frac{D}{t}}{t} \\
\mathrm{~d} & =\frac{71.025,6 \mathrm{Ton}}{357} \\
\mathrm{~d} & =198,9 \text { Ton }
\end{array}
$$

Maka titik pemesanan ROP adalah:

$\mathrm{R}=\mathrm{dL}+\mathrm{n}$

$\mathrm{R}=198,9 \times 2+2.588,9$

$\mathrm{R}=397.8+2.588,9$

$\mathrm{R}=2.986,7$ Ton

\section{Perbandingan}

Hasil perhitungan dengan menggunakan kebijakan perusahaan dan menggunakan metode EOQ telah diketahui, sehingga dapat dibandingkan untuk memperoleh hasil yang lebih efisien. Perbandingannya yaitu dapat dilihat dari jumlah pembelian bahan baku optimal, frekuensi pemesanan, total biaya persediaan, persediaan pengaman dan kapan seharusnya perusahaan memesan kembali bahan baku.

Tabel Perbandingan Kebijakan Perusahaan Dengan Metode EOQ

\begin{tabular}{|r|l|l|l|l|l|}
\hline \multirow{2}{*}{ No } & & \multicolumn{3}{|l|}{ Kebijakan perusahaan } & \multicolumn{2}{l|}{ Metode EOQ } \\
\cline { 3 - 6 } & Keterangan & $\mathbf{2 0 1 4}$ & $\mathbf{2 0 1 5}$ & $\mathbf{2 0 1 4}$ & $\mathbf{2 0 1 5}$ \\
\hline $\begin{array}{l}\text { Pembelian } \\
\text { rata-rata bahan } \\
\text { baku }\end{array}$ & $5.764,3$ Ton & $5.918,8$ Ton & 1.505 Ton & 1.467 Ton \\
\hline 2. & $\begin{array}{l}\text { Total biaya per } \\
\text { periode }\end{array}$ & Rp.9.029.344 & Rp.9.955.224 & Rp.4.413.214 & Rp.4.648.627 \\
\hline 3. & $\begin{array}{l}\text { Frekuensi } \\
\text { pemesanan }\end{array}$ & $42 \mathrm{kali}$ & $32 \mathrm{kali}$ & $46 \mathrm{kali}$ & $48 \mathrm{kali}$ \\
\hline 4. & Safety stock & - & - & $3.164,7$ Ton & $2.588,9$ Ton \\
\hline 5. & Re Order Point & - & - & $3.552,3$ Ton & $2.986,7$ Ton \\
\hline
\end{tabular}

Sumber: PT Bumi Sarimas Indonesia yang sudah diolah tahun 2014 dan 2015 
Jadi dapat diketahui perbandingan antara kebijaksanaan yang digunakan perusahaan dengan menggunakan metode EOQ: Pembelian bahan baku optimal tiap kali pesan pada tahun 2014 dan 20151.505 ton dan 1.467 Ton sedangkan menurut kebijakan perusahaan adalah 5.764,3 Ton dan 5.918,8 Ton. Total biaya per periode yang optimal pada tahun 2014 dan 2015 adalah Rp.4.413.214 dan Rp.4.648.627 sedangkan total biaya per periode menurut kebijakan perusahaan adalah Rp.9.029.344 dan Rp.9.955.224. Frekuensi pembelian bahan baku optimal pada tahun 2014 dan 2015 adalah 46 kali dan 48 kali sedangkan menurut perusahaan adalah 42 kali dan 32 kali. Kuantitas persediaan pengaman (Safety stock) yang dibutuhkan perusahaan pada tahun 2014 dan 2015 adalah 3.164,7 Ton dan 2.588,9 Ton. Sedangkan menurut perusahaan tidak kuantitas pengaman. Waktu pemesanan kembali (Re Order Point), waktu yang tepat adalah pada saat persediaan bahan baku didalam gudang tahun 2014 dan 2015 yaitu 3.552,3 Ton dan 2.986,7 Ton. Sedangkan kebijaksanaan perusahaan tidak ada waktu pemesanan kembali atau Re order Point.

\section{Penutup}

Teknik pengolahan bahan baku kelapa pada PT. Bumi Sarimas Indonesia sudah mengikuti prosedur yang ditetapkan perusahaan mulai dari pembelian, penerimaan, pengumpulan dan penyimpanan, pengeluaran, persiapan bahan baku serta proses pengolahan bahan baku kelapa untuk produksi santan. Penggunaan bahan baku daging kelapa terhadap produksi hasil santan di PT. Bumi Sarimas Indonesia Kabupaten Padang Pariaman secara umum belum efisien. Jumlah kebutuhan bahan baku yang ekonomis dan optimal dengan menggunakan metode EOQ pada tahun 2014 dan tahun 2015 adalah 1.505 Ton dengan frekuensi pemesanan 46 kali dalam satu tahun dan 1.467 Ton dengan frekuensi pemesanan 48 kali dalam setahun. Kuantitas persediaan pengaman atau Safety stock pada tahun 2014 dan 2015 dengan menggunakan metode EOQ kuantitas persediaan pengaman adalah 3.164,7 Ton dan 2.588,9 Ton. Pemesanan kembali (Re Order Point) menurut perhitungan EOQ pada tahun 2014 dan 2015 berada pada titik 3.552,3 Ton dan 2.986,7 Ton. Implementasi manajerial PT. Bumi Sarimas Indonesia tentang penggunaan bahan baku yang efisien dapat dilakukan dengan planning (perencanaan) terhadap kebutuhan penggunaan bahan baku, organizing (pengorganisasian) terhadap bidang kegiatan proses produksi santan kelapa, actuating (pelaksanaan) kegiatan yang sesuai dengan standar operasionan prosedur (SOP) perusahaan dan controling (pengawasan) terhadap bahan baku, kontrol pada mesin yang digunakan.

\section{Daftar Pustaka}

Adi, Widoso, (2009). Analisis Perencanaan Produksi dengan Pengendalian Persediaan Bahan Baku pada Unit Usaha Sarana Produksi Ternak Koperasi Agro Niaga Jabung Malang. Universitas Islam Negeri Maulana Malik Ibrahim.

Assauri, Sofjan, (1980). Management Produksi. Jakarta: Lembaga Penerbit Fakultas Ekonomi Universitas Indonesia.

Carter, William, (2006). Akuntansi Biaya. Penerjemah Krista. Edisi 13.Jakarta: Selemba Empat

Dewi, Ita Yuliana, (2010). Analisis Pengendalian Persediaan Bahan Baku Kertas CD Roll With Safety Stock pada CV. Adinugraha. Universitas Surakarta.

Ginting, Rosnani, (2007). Sistem Produksi. Edisi Pertama. Yogyakarta: Graha Ilmu. 
Habibi, Reza Pradana Surya, (2013). Perencanaan Persediaan Bahan Baku Dengan Metode Sistem Q Dan Sistem P Pada PT. Papertech Indonesia Unit II. Universitas Islam Sunan Kalijaga Yogyakarta.

Hadiguna, Rika Ampuh, (2009). Manajemen Pabrik Pendekatan Sistem Untuk Efisiensi dan Efektifitas. Edisi Pertama. Jakarta: Bumi Aksara.

Haming, Murdifin \& Mahfud Nurnajamuddin, (2012). Manajemen Produksi Modern Operasi Manafaktur dan Jasa. Edisi Kedua. Jakarta: Bumi Aksara

Hasan, Iqbal, (2011). Pokok-pokok Materi Statistik I (Statistik Deskriptif). Jakarta: Bumi Aksara

Kasmir, (2013). Pengantar Manajemen Keuangan. Kencana: Jakarta

Libby, Robert dkk, (2008). Akuntansi Keuangan. Diterjemahkan oleh Agung Saputra. Yogyakarta: Perpustakaan Nasional.

Lukman, Syamsuddin, (2007). Manajemen Keuangan Perusahaan Konsep Aplikasi Dalam Perencanaan, Pengawasan, dan Pengambilan Keputusan. Jakarta: PT. Grarindo Persada.

Martani, Dwi dkk, (2012). Akuntansi Keuangan Menengah Berbasis PSAK. Jakarta: Selemba Empat.

Radiani, Dian, (2004). Peranan Pengendalilan Internal Persediaan Barang dagangan Dalam Menunjang Efektivitas Pengelolaan Persediaan Barang Dagangan. Universitas Widyatama Bandung

Sangadji, Etta Mamang \& Sopiah, (2010). Metodologi Penelitian: Pendekatan Praktis dalam Penelitian. CV Andi: Yogyakarta

Syafitri, Lili, (2014). Analisis Sistem Pengendalian Persediaan Barang Dagang Pada PT. Sungai Budi Palembang. STIE MD Palembang

Terry, George R, (2009). Prinsip-prinsip Manajemen. Penerjemah J. Smith. Bumi Aksara: Jakarta. 